\title{
ВСПОМОГАТЕЛЬНЫЕ РЕПРОДУКТИВНЫЕ ТЕХНОЛОГИИ: ДЕТИ БУДУТ, НО КАКИЕ?
}

\author{
Русанова Н.Е.
}

Вспомогательные репродуктивные технологии (ВРТ) менее чем за полвека своего существования решили проблему бесплодия, но рост рождаемости не превысил 5\%. При этом возникли новые проблемы, вызванные не медицинской, а организационной и социальной спецификой: в России в 2016 2. проводилось на треть больше циилов ЭКО, чем выявлялось бесплодия. «Лишние» иикль реализуются в коммерческих программах BPT, чаще всего в суррогатном материнстве. Интернационализаџия рынка ВРТ приводит к тому, что анонимность иностранных доноров, высокая стоимость донорского материала и не полное соответствие стандартов отбора не позволяют провести генетический анализ, результатом чего становится рождение больного ребенка. Необходим поиск новых организационных решений, устраивающих и репродуктивные клиники, и паџиентов.

DOI: $10.20537 /$ mce2020econ12

«Судьба России, её историческая перспектива зависит от того, сколько детей родится в российских семьях через год, через пять, десять лет, какими они вырастут». Послание Президента РФ В.В. Путина Федеральному Собранию 15.01.2020 [1]

Введение. Вспомогательные репродуктивные технологии (ВРТ) существуют в мире менее 50 лет, но за это время заметно изменили рождаемость. Современная рождаемость регулируется фертильным населением, для которого важны социально-экономические факторы, а также инфертильным и субфертильным, где на первый план выходят факторы медицинские.

Еще столетие назад каждый десятый брак был бесплоден абсолютно и не имел перспектив рождения в нем детей, а каждый третий относительно, т. е. требовал медицинского вмешательства в процесс зачатия и вынашивания ребенка. По статистике некоторых лечебных учреждений, до трети всех обратившихся пациенток, чаще всего в 
возрасте максимальной биологической способности к зачатию, предъявляли жалобы на бесплодие либо имели бесплодие в анамнезе [2, c. 238]. ВРТ решили проблему бесплодия, но оказалось, что даже в странах с максимальной доступностью этих высокотехнологичных дорогостоящих методов, где практически каждый пациент с нарушением репродуктивной функции, получает бесплатное лечение с помощью ВРТ, рождаемость повышается лишь на 4.5-5\%. Однако даже такой сравнительно небольшой рост повлек за собой новые проблемы, причем вызванные не медицинской, а организационной и социальной спецификой.

Результаты. Главным демографическим результатом широкого применения ВРТ стало изменение рождаемости: количественное - в России в 2017 г. появилось на свет 33748 новорожденных, зачатых с помощью экстракорпорального оплодотворения (ЭКО) (против 7184 в 2007 г.) и качественное, реализуемое через «нестандартное» родительство при чайлд-фри, социальном бесплодии, суррогатном, позднем и «отсроченном» материнстве, отборе детей по заданным биологическим характеристикам. За 2007-2016 гг. рост числа ЭКОрождений существенно превышал аналогичный показатель для «естественных рождений»:

- суммарный коэффициент рождаемости (СКР) вырос на 23.9\% (с 1.42 до 1.76);

- доля ЭКО-рождений — в 3.8 раза (с 7184 до 30770 чел.);

- общее число родившихся — на $15.3 \%$ (с 1610122 до 1856918 человек);

- число «естественных рождений» - на $13.9 \%$ (с 1602938 до 1826148). [Рассчитано по: 3, с. 56; 4]

Хотя число ЭКО-рождений в России не превышают $1.7 \%$ от общего числа родившихся, но именно среди них реализуются репродуктивные потребности населения, соответствующие второму демографическому переходу, и если в 2005 г. на один цикл ЭКО приходилось три впервые установленных диагноза «бесплодие», то в 2013 г. соотношение уравновесилось, а в 2016 г. циклов ЭКО проводилось на треть больше, чем выявлялось бесплодия (рис. 1): Министр здравоохранения России в своем выступлении отметила: «Значительно увеличилась доступность экстракорпорального оплодотворения. [В 2018 г.] проведено свыше 78 тыс. бесплатных процедур ЭКО, что на 21\% больше, чем годом ранее. Это позволило появиться на свет 28.5 тысячам детей» [5]. 
Анализ и моделирование экономических и сочиальных прочессов - МКО - 2020 Analysis and modeling of economic and social processes - MCE - 2020

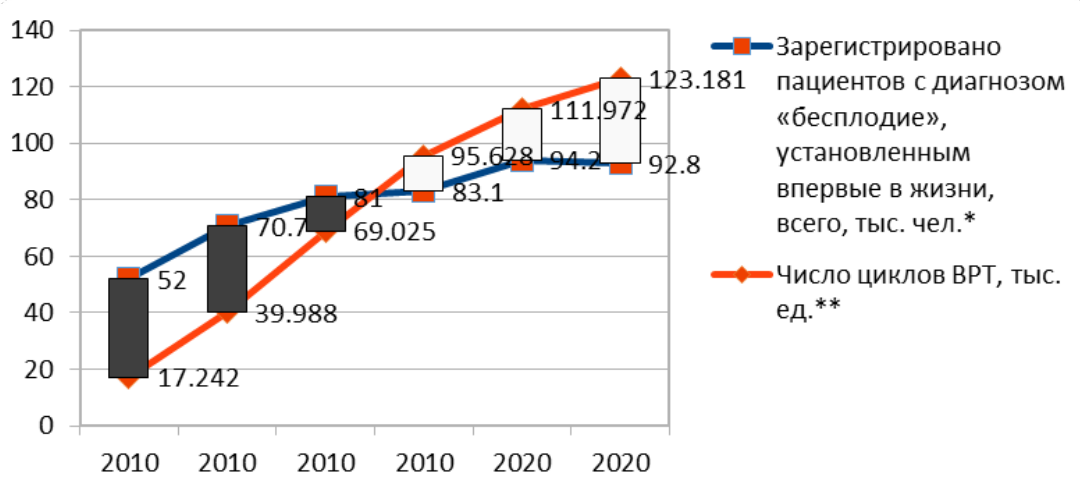

Рис. 1. Численность пациентов с диагнозом «бесплодие» и числом циклов ВРТ. Источник: *[6], **[4]

Можно выделить следующие проблемы:

- Чайлд-фри - сознательный отказ от рождения детей, иногда в расчете на то, что «моих детей родят другие» и участие для этих целей в донорских программах.

- Социальное бесплодие - коррекция «бесплодия» у одиноких, в том числе репродуктивно здоровых женщин, не имеющих фактического супруга (в медицинских картах диагноз ставится как «социальный фактор бесплодия»), в соответствии с ст. 55 Ф3 «Об основах охраны здоровья граждан в Российской Федерации» (эта программа всегда выполняется с донорским материалом и финансируется по системе ОМС).

- «Отсроченное материнство» - изъятие у молодых девушек (в возрасте около 20 лет) нескольких созревших яйцеклеток, криоконсервация для последующего ЭКО с собственными клетками.

- Определение пола «по социальным показаниям» практикуют в некоторых странах, но в России запрещено с 2011 г. [7, с.55].

- «Усыновленный эмбрион» предполагает решение будущих родителей о судьбе эмбрионов, которые останутся после ЭКО: донорство (анонимное или открытое?), криоконсервация (хранение сколько?), утилизация (для каких целей?), а также установление правовых приоритетов при разводе. 
- Суррогатное материнство $(\mathrm{CM})$ - одна из наиболее популярных и при этом наиболее спорных программ ВРТ. В отличие от других программ ВРТ здесь априори предполагается, как минимум, один дополнительный участник - «третье лицо», что сразу делает ее юридически и финансово уязвимой. Также СМ считается этически небезупречной, нарушающей традиционные взаимосвязи «мать-дитя» и создающей возможности «эксплуатации» женщины. Такие институциональные сложности приводят к тому, что в некоторых странах СМ запрещено полностью или частично, но в России ограничений почти нет, СМ формально одинаково доступно и для женщин, и для мужчин независимо от их возраста и брачного статуса; под запретом лишь «полное» (гестационное) СМ, когда суррогатная мать одновременно является и генетической матерью ребенка, а также официальная регистрация двух отцов или двух матерей у одного ребенка.

В России СМ - одна из наиболее «продвинутая» средствами массовой информации программ ВРТ, и на запрос: «суррогатное материнство в Москве форум» в мировом поиске находится более 70 млн ответов. Но достоверной информации о СМ недостаточно, часто участники скрывают реальный состав программы, и даже данные о СМ в Национальный регистр ВРТ отправляют не все клиники (например, в 2015 г. таких было лишь 58.9\%). Однако по данным РАРЧ за 20052017 гг. в РФ было проведено 11196 циклов СМ с колебаниями по частоте применения от 1.2 до $1.7 \%$ в разные годы (в среднем 1.4\%). Это свидетельствует о том, что доля патологии, при которой показано СМ, остается практически неизменной, а увеличение абсолютного числа лечебных циклов СМ является следствием доступности этого вида медицинской помощи для населения [8].

При этом доля СМ среди всех циклов ВРТ остается относительно стабильной уже около 10 лет (табл. 1). Число циклов ВРТ с участием суррогатных матерей за это время выросло в 4 раза, а число родов - в 4.4 раза (рассчитано по [4]). Имеющиеся данные не позволяют точно определить, сколько детей родилось у суррогатных матерей, т. к. известны не все исходы их беременностей (в 2016 г. неизвестен исход $9.2 \%$ беременностей), а доля многоплодия составляет в разные годы 18 $25 \%$. Еще меньше информации о том, сколько детей имеют свидетельства о рождении с прочерком в графе «мать», хотя в 2017 г. в СанктПетербурге после СМ родилось 162 ребенка, а в 2018 г. восьмерых детей зарегистрировали одинокие отцы, четверых - одинокие матери [9]. 
Анализ и моделирование экономических и сочиальных прочессов - МКО - 2020

Analysis and modeling of economic and social processes - MCE - 2020

Таблица 1. Суррогатное материнство в России. Источник: [4].

\begin{tabular}{|l|c|c|c|c|c|}
\hline & 2007 & 2010 & 2013 & 2016 & 2017 \\
\hline Число циклов ВРТ с участием СМ & 367 & 648 & 855 & 1465 & 1777 \\
\hline $\begin{array}{l}\text { Доля циклов ВРТ с участием СМ } \\
\text { среди всех циклов ВРТ \% }\end{array}$ & 1.4 & 1.6 & 1.2 & 1.2 & 1.3 \\
\hline Число родов СМ & 107 & 193 & 254 & 470 & 567 \\
\hline
\end{tabular}

Современное репродуктивное законодательство РФ признано одним из самых лояльных в мире, а СМ регламентируется Семейным Кодексом РФ (вопросы рождения ребенка суррогатной матерью и его регистрация, условия, при которых генетические родители могут считаться официальными), Федеральным законом о применении ВРТ в РФ (Ф3 №323 «Об охране здоровья»: основные моменты внедрения ВРТ, их цель, задачи, категории людей, которые могут воспользоваться ВРТ) [7], отраслевыми инструкциями Министерства здравоохранения РФ [(медицинские показания для женщин, при которых показана, абсолютно противопоказана либо ограничена программа СМ, например, при участии в программах СМ здоровых женщин (отказ от беременности, чтобы сохранить фигуру, работу, статус и т. д.)], однако СМ как современный вариант женской занятости остается за пределами Трудового кодекса РФ. В результате возможны ситуации, когда генетические родители отказываются от ребенка, родившегося с патологией, после чего контракт с суррогатной матерью полностью аннулируется, и она оказывается официальной матерью чужого больного ребенка. «В России нет официальной статистики отказов от детей, рожденных в результате программы СМ. Известны единичные случаи, при том, что всего за время существования программы в нашей стране родилось около 3500 детей» [8]. С другой стороны, суррогатная мать имеет возможность в последний момент передумать и не отдавать новорожденного его генетическим родителям, что особенно чувствительно при одиноком отцовстве.

Одной из самых обсуждаемых проблем является здоровье ЭКОдетей, однако большинство локальных исследований показывает, что:

- ЭКО-дети абсолютно не отличаются от своих сверстников;

- заболеваемость ЭКО-детей сопоставима с заболеваемостью детей, зачатых естественным путем.

- часто ЭКО-дети развиваются лучше, чем их ровесники, благодаря повышенному вниманию родителей. 
Есть и социально-психологические вопросы: нужно ли скрывать, что ребенок рожден методом ЭКО? А если это донорский половой материал? Чаще всего возникает два типа ситуаций: когда родители не знают, рассказывать ли ребенку об обстоятельствах его появления на свет или же сохранить тайну, и когда уже взрослые дети вдруг начинают понимать, что в их жизни есть какие-то тайны, связанные с рождением. Проще всего решается вопрос, когда происходит ЭКО с половыми клетками супругов это допускает даже церковь, сложнее всего - когда ребенок рождается от донорской яйцеклетки, оплодотворенной донорским сперматозоидом, и у родителей появляется генетически чужой ребенок; в большинстве таких случаев требуется помощь психологов.

Хотя перечень показаний для ЭКО, расширяется, общей тенденцией является более быстрый рост числа циклов ЭКО по сравнению с медицинской потребностью в них; «лишние» циклы будут реализованы в коммерческих программах ВРТ, наиболее распространенной из которых является суррогатное материнство, в том числе международное. Интернационализация рынка ВРТ создает свои проблемы, например, при донорстве половых клеток, когда анонимность иностранных доноров, высокая стоимость донорского материала и неполное соответствие стандартов отбора не позволяют провести предимплантационный генетический анализ, в результате чего рождается больной ребенок.

BPT в условиях пандемии. Пандемия нового вируса COVID-19, объявленная Всемирной организацией здравоохранения в марте 2020 г., выявила дополнительные риски современных ВРТ. Длинный инкубационный период (до 14 дней), высокая заразность (коэффициент около 3), бессимптомность у $30 \%$ и тяжелые осложнения, вплоть до летального исхода, у $15 \%$ инфицированных, определили решение профессиональных сообществ репродуктологов во всем мире приостановить проведение процедур ВРТ на период пандемии, в том числе «для снижения неизвестного риска вертикальной передачи инфекции у пациенток с подтвержденным COVID-19». Это были превентивные меры, поскольку отсутствовали четкие доказательства негативного влияния вируса на беременность и здоровье новорожденных, но даже при необходимости срочного сохранения фертильности, например, у онкологических больных, либо для пациентов, уже вступивших в протоколы ВРТ, рекомендовалась криоконсервация гамет, эмбрионов или тканей [10]. Об изменении ситуации было сообщено лишь в конце апреля, поскольку «по мере того как пандемия COVID-19 
стабилизируется, возвращение к нормальной повседневной жизни также будет означать необходимость возобновления проведения ВРТ... по любым клиническим показаниям в соответствии с местными правилами». Рекомендации предусматривали криоконсервацию биологического материала, если в процессе лечения у пациентки выяснялся положительный статус COVID-19 [2].

По мнению репродуктологов, «как таковых рекомендаций воздерживаться от наступления беременности для общества в целом в сложившихся условиях нет». Однако мировому профессиональному сообществу необходимо «объединиться ради создания общего плана по возобновлению репродуктивной помощи после завершения общемировых карантинных мер, чтобы ответить на вопросы: Когда? Как? Кому? С использованием каких мер предосторожности / диагностических тестов возобновить проведение ЭКО» [11].

Заключение. Стабильное развитие ВРТ сделало их неотъемлемой частью современной рождаемости, изменяющей демографические характеристики и тенденции, но одновременно зависимой от социальноэкономической ситуации не только в стране, но и в мире. Решив медицинскую проблему бесплодия, ВРТ не только создали новые, не связанные с физиологией рождения, но и сами оказались зависимыми от отраслевых и общемировых тенденций, как это показывает пандемия заболевания, далекого от репродуктологии. Подобные ситуации требуют дополнительных исследований и организационных решений, адекватных для национальной системы репродуктивной помощи и ее пациентов, т. к. «демография - это сфера, где нет какого-то универсального ... решения» [1].

\section{СПИСОК ЛИТЕРАТУРЫ}

1. Послание Президента РФ В.В. Путина Федеральному Собранию 15.01.2020. URL: http://www.kremlin.ru/events/president/news/62582

2. Сайфитдинова А.Ф. Особенности биологии COVID-19 и связанные с этим риски для репродуктивной медицины. URL: http://rahr.ru/d_index/saicov.pdf

3. Демографический ежегодник 2017. URL: https://www.gks.ru/storage/mediabank/demo17.pdf

4. Регистр центров BPT России. Отчет за 2017 год. URL: http://rahr.ru/d_registr_otchet/RegistrART2017.pdf 
5. Выступление Министра Вероники Скворцовой на заседании итоговой коллегии Минздрава России 24.04.2019. URL:

https://www.rosminzdrav.ru/news/2019/04/24/11389-vystuplenie-ministra-veronikiskvortsovoy-na-zasedanii-itogovoy-kollegii-minzdrava-rossii

6. Здравоохранение России 2017. URL: http://www.gks.ru/free_doc/doc_2017/zdrav17.pdf

7. Федеральный закон от 21.11.2011 №323-Ф3 (ред. 27.12.2018 с изменениями, вступившими в силу с 31.01.2019) «Об основах охраны здоровья граждан в Российской Федерации» URL:

https://minzdrav.gov.ru/documents/7025-federalnyy-zakon-ot-21-noyabrya2011-g-323-fz-ob-osnovah-ohrany-zdorovya-grazhdan-v-rossiyskoy-federatsii

8. Ответы на вопросы главного редактора журнала "Дело", г. Самара Виктории Петровой о суррогатном материнстве 08.04.2020 URL: http://rahr.ru/d index/04 20\%20delo.pdf

9. Суррогатное материнство для одиноких: разрешено, но запрещено. Официальный сайт по правам ребенка в Санкт-Петербурге. URL: http://www.spbdeti.org/id7087

10. Veiga A., Gianaroli L., Ory S., Horton M., Feinberg E., Penzias A. Assisted reproduction and COVID-19: a joint statement of ASRM, ESHRE and IFFS // Human Reproduction Open, v. 2020(3), 2020. DOI: 10.1093/hropen/hoaa033

11. Обзор экспертного вебинара по теме коронавирусной инфекции (COVID19) и ее возможном влиянии на работу репродуктивной системы 9 апреля 2020 г. URL: http://rahr.ru/d_index/Mercovi.pdf

\section{ASSISTED REPRODUCTIVE TECHNOLOGIES: THERE WILL BE CHILDREN, BUT HOW MIGHT IT AFFECT THEM?}

\section{Rusanova N.E.}

Assisted reproductive technologies (ART) have solved the problem of infertility in less than half a century, but the birth rate has not exceeded 5\%. At the same time, new problems arose, caused not by medical, but by organizational and social specifics: in Russia in 2016, a third more IVF cycles were performed than infertility was detected. "Extra" cycles are implemented in commercial ART programs, most often in surrogacy. The internationalization of the ART market leads to the fact that the anonymity of foreign donors, the high cost of donor material and not full compliance with selection standards do not allow for genetic analysis, which results in the birth of a sick child. We need to find new organizational solutions that suit both reproductive clinics and patients. 